\title{
The Impact of Targeted Poverty Alleviation on Ruoguo Villagers' Health Consciousness Based on Village Revitalization Work of School of Traditional Chinese Medicine of Jinan University
}

\author{
Yahe Huang, Dongmei Xiao, Yi Wang, Yixuan Li \\ School of Traditional Chinese Medicine of Jinan University, Jinan University, Guangzhou, China \\ Email: HYH219@jnu.edu.cn
}

How to cite this paper: Huang, Y. H., Xiao, D. M., Wang, Y., \& Li, Y. X. (2020). The Impact of Targeted Poverty Alleviation on Ruoguo Villagers' Health Consciousness Based on Village Revitalization Work of School of Traditional Chinese Medicine of Jinan University. Advances in Applied Sociology, 10, 504-512.

https://doi.org/10.4236/aasoci.2020.1012030

Received: December 2, 2020

Accepted: December 26, 2020

Published: December 29, 2020

Copyright $\odot 2020$ by author(s) and Scientific Research Publishing Inc. This work is licensed under the Creative Commons Attribution International License (CC BY 4.0).

http://creativecommons.org/licenses/by/4.0/

\begin{abstract}
RuoGuo village is one of the many poverty-stricken areas in China. In recent years, The School of Traditional Chinese Medicine of Jinan University has actively implemented the party's guidelines for poverty alleviation work, adopting various forms and methods to carry out poverty alleviation work in RuoGuo Village, which has achieved initial results. Through this survey, we can see the effectiveness of the JNU's poverty alleviation work, and recognize the current situation of Zhuanguo Village so that the next poverty alleviation work can be more targeted. By summarizing the merits and shortcomings of Jinan University's poverty alleviation work, We can improve working methods for the targeted poverty alleviation in Runguo Village, and accumulate the experience of targeted poverty alleviation, which is also a way to actively respond to the national targeted poverty alleviation policy. Besides, we can provide a certain reference value for the targeted poverty alleviation work in other regions.
\end{abstract}

\section{Keywords}

Poverty Alleviation, Extracurricular Classes Education, Ruoguo Village

\section{Research the Problem}

Since the end of 2015, the School of Traditional Chinese Medicine of Jinan University began to carry out the special poverty alleviation project for Ruoguo village. Every year the School relevant leader would have an insight into the living 
conditions of the local residents, at the same time, they would provide financial assistance and material assistance for daily living the holiday students from the Sc School Traditional Chinese Medicine volunteered to org bring scientific, literacy knowledge and offer medical service cam organized free clinicslth education, volunteer teaching and other colorful activities that provided the strength of the youth for the improvement of their construction level. The School of Traditional Chinese Medicine of Jinan University has developed an area of poverty alleviation for many years. At this stage, we should respond more to the national call for targeted poverty alleviation. In the critical stage of building a well-off society in an all-round way, we should test our effectiveness of poverty alleviation work so that we can develop a targeted poverty alleviation work in the future. Therefore, the main topic of this survey was the impact of targeted poverty alleviation in School of Traditional Chinese Medicine of Jinan University on Ruoguo Village in recent years.

\section{Research Background}

The whole village cultivated land is 2611 acres, forest land is 2962.7 acres, it has jurisdiction over 18 villagers group, 10 natural villages, 565 households, 2152 people, the existing village "two committees" cadres 544 party members. The main industry of the village is mainly agriculture, and the main cash crops are yellow smoke, rice, peanuts and so on.

However, because of its geographical isolation and lack of transportation, the economic development of the village came to an almost standstill. In 2009, the village collective economic income was 15,000 yuan. In recent years, the collective economic income of the village was only 25,000 yuan per year.

\section{Research Significance}

Over the past three decades of reform and opening-up, hundreds of millions of Chinese have shed the stigma of poverty. However, China still faces an arduous task in poverty alleviation (Huang, 2019). According to the latest data, by the end of 2013, There were still 82.49 million people living in poverty in rural areas according to China's poverty alleviation standards (China Poverty Alleviation and Development Yearbook Editorial Committee, 2015). The problem of underdeveloped areas in poor areas has not changed fundamentally. In terms of people's livelihood, the disadvantaged groups often have more and stronger demands, so they need more attention and help. Rouguo village is a small microcosm of China's many poor areas, in recent years, the School of Traditional Chinese Medicine of Jinan University actively implement the party for the poverty alleviation work guidance, take many forms and methods of Rouguo village in the poverty alleviation work, It is beginning to bear fruit, on the significance of this research is that the practical and realistic understanding of the jinan university poverty relief work after the results, identify Rouguo village's current situation so that the poverty alleviation work more targeted, summarizes the 
merits of poverty alleviation, jinan university and deficiencies need to improve place, summarized for Rouguo village precision poverty alleviation work method, accumulated accurate experience for poverty alleviation, It also responds to the national policy of targeted poverty alleviation, and provides certain reference value for the targeted poverty alleviation work in other regions.

\section{Data Collection Methods}

This research is mainly conducted in the following ways.

\subsection{Conduct Investigation and Research in the Form of Questionnaire}

Compile the information you need to know into questions, send it out in the form of questionnaire, and then collect the percentage of each question in the questionnaire to obtain the survey information. The electronic questionnaire was jointly produced, and then a large number of survey results were collected by the whole group members through their social circles (WeChat circle of friends, WeChat, QQ group messages, QQ space, etc.). In addition, considering the many impoverished people in Rouguo village who were unable to participate in the questionnaire online, the team will also produce a paper version of the questionnaire, which will be widely distributed in the survey destinations. For those with less education, we asked questions according to the questionnaire and recorded their answers, so that the results could be faithfully reflected in the questionnaire, so as to collect a large number of samples. Finally, through the division of labor in the group, the obtained results were collected, use statistical methods, calculate the number of people in each interval, and corresponding results were obtained through objective analysis. The mutual cooperation between online and offline methods not only broadens the ways for the masses to participate in research and enhances their cooperation, but also improves the scientific nature and rigor of the research.

\subsection{Conduct Research in the Form of Interviews (Zhou, 2019)}

Through visiting and investigating the people with difficulties in life, as well as the poverty-stricken households recognized by the government, the interviewees will be determined. Through targeted interviews, representative poverty-stricken households were selected for special in-depth interviews, so as to provide reference points for the collection of research results, analysis and discussion. Targeted interviews not only supplement the defects of samples with insignificant characteristics, but also provide authentic and credible arguments for poverty alleviation research, improve the authenticity of the research, and help the research working group grasp the accuracy of the research direction. In addition, the interview in this research will also communicate with local cadres who are engaged in poverty alleviation work, find out their specific situation about Rouguo village and develop a specific policy that was implemented, and observe the research work from a higher perspective, so as to fully grasp the actual progress 
and significance of poverty alleviation work, thus ensuring the objectivity of the research results and analysis.

\subsection{Collect Relevant Literature for Research}

To obtain national government poverty alleviation policies and against Ruoguo village poverty alleviation work situation, involving Ruoguo village of relevant reports and literatures, and integrate research information needed to help researchers better understand the research background and theme and improve the accuracy of the research direction and research the effectiveness of the result.

\section{Sampling Method}

The sample location in this survey was Ruoguo village, considering that villagers need to work in agriculture or work outside, or due to the impact of weather conditions such as rainfall, and uncertainly about villagers' mobility. As a result, the samples collected cannot be estimated more accurately. In order to ensure the scientific selection of research samples, the sampling method of this research is selected according to the following conditions:

$1)$ When the number of samples is small $(\leq 80)$, the lottery method is adopted. Generally speaking, the lottery method is to write the number of $\mathrm{N}$ individual Numbers in the population of the investigated people on the number sign, put the number sign in a container, after mixing evenly, draw a number sign from it every time, draw $\mathrm{N}$ times in a row, then get a sample with a capacity of $\mathrm{N}$.

2 ) When the number of samples is large (>80), the equal-ratio sampling method in the stratified sampling method is adopted. Stratified sampling refers to a method in which the population is divided into mutually disjoint layers during sampling, and a certain number of individuals are extracted independently from each layer according to a certain proportion, and the individuals taken from each layer are combined together as samples. Where, the ratio of the number of individuals drawn by each layer to the number of individuals in the class is the same.

\section{Basic Information of the Sample}

At present, the total population of the village is about 2152 people, and the economic income of the villagers is mainly based on planting yellow smoke, rice and out-migrating for work. After the first round of investigation, a total of 116 people were identified from 48 relatively poor households in the village, showing in Figure 1, including 82 people from 24 poor households, 21 people from 11 low-income households and 13 people from 13 households of five households, showing in Figure 2. More than 11 percent of the village's population is poor, with an annual per capita income less than 2000 yuan. The whole village cultivated land is 2611 acres, forest land is 2962.7 acres, it has jurisdiction over 18 villagers group, 10 natural villages, 565 households, 2152 people, the existing village "two committees" cadres 544 party members. The main industry of the 


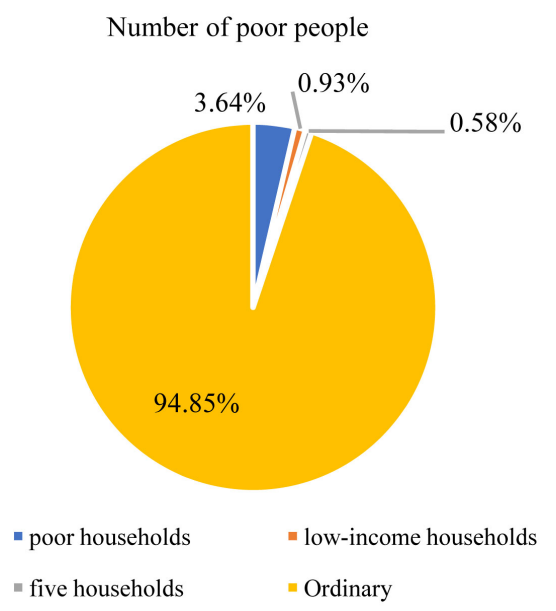

Figure 1. The number of poor people of Ruoguo village.

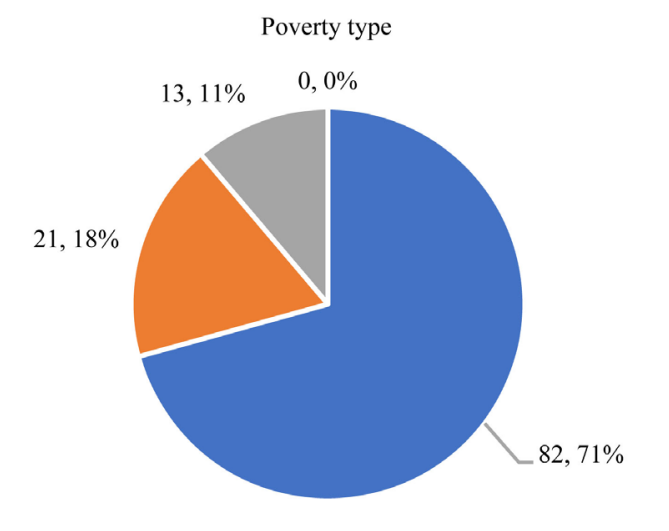

" poor households " low-income households " five households.

Figure 2. The poverty type of Ruoguo village.

village is mainly agriculture, and the main cash crops are yellow smoke, rice, peanuts and so on.

\section{Variable Design}

In this survey, we set the following variables:

Discrete variables refer to the variables that divide things into two or more classes according to certain standards. In our survey, we separated the villagers who lived primarily through their average annual income into those who were impoverished or those who were not, and poor households are our main target (Bi, 2016).

A continuous variable is a variable that directly represents a change in the quantity of the same class of things by a set of data. In this survey, we used the average annual income level to reflect the changes in the living standards of poor households.

Dependent variable refers to the variable that cannot affect other variables but is changed by external interference. In this survey, the poor households were affected by the targeted poverty alleviation policy and their living standard 
changed.

In the questionnaire, 61 villagers were interviewed primarily for their article. Among them, showing in Table 1, 65.57\% have annual household income below $10,000,25.31 \%$ have annual household income between 10,000 and 20,000, and the rest of the respondents have annual household income scattered in various intervals (see the attached questionnaire for details). $78.68 \%$ of the respondents have a family size of 4 or more. $75.41 \%$ of the respondents were mainly engaged in farming. According to the survey data, the reasons for the low annual income of the respondents may be related to the larger family size and the involvement in farming.

Showing in Figure 3,57.38\% of the respondents were received clinic service by the School of traditional Chinese medicine of Jinan University, reflects the School of traditional Chinese medicine work wide audience in the area of poverty alleviation, poverty alleviation work scope is larger, Ruogou villagers took participate in or know of traditional Chinese medicine academy of poverty alleviation activities have free clinic project, the number of accounts for $60.66 \%$ of the total number of respondents, and know that there are health knowledge popularization, the number of $54.1 \%$ of the total number of investigation. In the anti-poverty activities carried out by the School of Traditional Chinese Medicine, $59.02 \%$ of the respondents believed that they had gained more knowledge about health, and $40.98 \%$ of the respondents believed that this had enriched the activities in the village. $45.9 \mathrm{Y}$ percent of the respondents believed that the quality of life had improved after poverty alleviation in the School of Chinese medicine. According to the survey data, poverty alleviation activities carried out by the School of Traditional Chinese Medicine have attracted a large number of audiences, whose main function is to popularize health knowledge and enrich the activities in the village.

Showing in Figure 4, 45.9 percent of the respondents believed that the quality of life had improved after poverty alleviation in the School of Traditional Chinese Medicine, 24.59 percent believed that the quality of life had not improved, and the remaining 39.51 percent believed that no significant change had been felt. $72.13 \%$ of the respondents agreed to support the School to continue its poverty alleviation work in the future. The survey data showed that the impact of the School of Traditional Chinese Medicine on poverty alleviation remained to be improved and the service came closer to the villagers' actual needs, but at the same time, the School's service was mostly approved and supported by most respondents who came across a wide area.

Table 1. An annual household income survey of Ruoguo village.

\begin{tabular}{cccc}
\hline \multicolumn{4}{c}{ An annual household income survey of Ruoguo village } \\
\hline Annual household income & Less than 10,000 & $10,000-20,000$ & others \\
\hline number & 40 & 15 & 6 \\
proportion & $65.57 \%$ & $25.31 \%$ & $9.12 \%$ \\
\hline
\end{tabular}




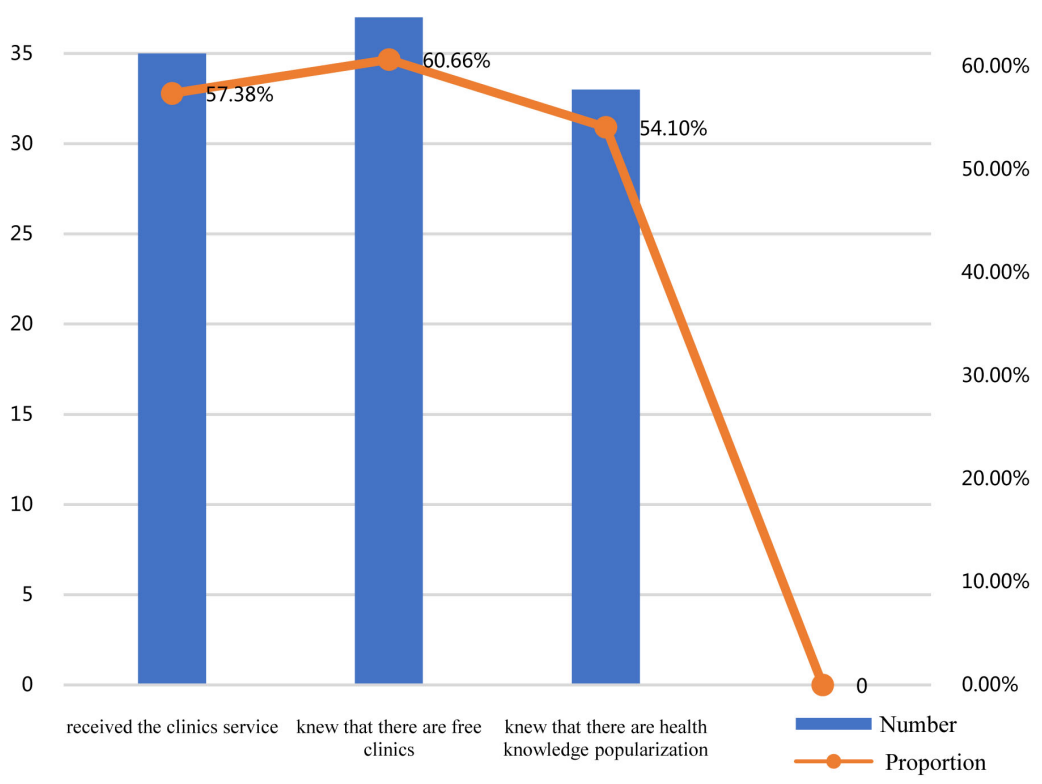

Figure 3. Free clinics and health knowledge popularization and publicity.

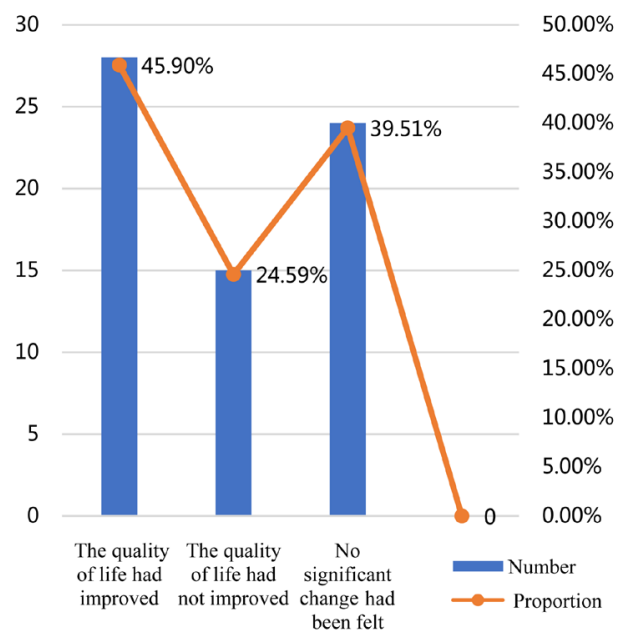

Figure 4. The impact of poverty alleviation activities on the quality of life of villagers.

In the questionnaires received 61 Suggestions, most respondents express affirmation for the work of School of traditional Chinese medicine, but the rest of the respondents think that the traditional Chinese medicine School poverty alleviation work is still worthy to be improved, such as hopes to increase the types of clinic service such as increasing shuangz dental examination and drugs, increase the number of activities held.

In this survey, we conducted an in-depth interview with two impoverished families who were sponsored primarily by the School of Traditional Chinese Medicine.

The reason for the low income of the two poor families is that the working population is small and the family members are seriously ill. Born disabled and 
unemployed. This reflects the diversity of poverty alleviation targets funded by the School of Traditional Chinese Medicine, and the precision of poverty alleviation targets. All of them have received consolation money and medicine subsidies from the School, which reflects that the materials provided by the School are targeted and individualized to the needs of different poor families. All of them are satisfied with the poverty alleviation services provided by the School.

\section{Research Conclusion}

Through this survey, we can see that more than $70 \%$ of the respondents are engaged in agricultural production, the number of family members is 4 or more, and $40 \%$ of the respondents have an annual income of less than 20,000, suggesting that improving agricultural production conditions, increasing agricultural output rate and production efficiency can be more targeted to alleviate poverty for agricultural producers.

In recent years, the School of Traditional Chinese Medicine (TCM) of Jinan University lacked about half of the villagers primarily through the poverty alleviation service provided by the School of Traditional Chinese Medicine. The Colleg's poverty alleviation offerings have initially grown in size, but there is still room for expansion. However, $40 \%$ of the respondents are still not familiar with the free clinic activities of the School of Traditional Chinese Medicine, so they see that our influence still needs to be improved and our publicity still needs to be strengthened.

The role of the poverty alleviation service of the School of Traditional Chinese Medicine is also reflected. It can be seen that the poverty alleviation service is consistent with the needs of the villagers, and has achieved initial results. The villagers have improved their health awareness and sense of happiness.

The villagers believed the improvement in the quality of life primarily through the poverty alleviation work of the School of Traditional Chinese Medicine of Jinan University in recent years, which shows that the School of Traditional Chinese medicine of Jinan University carried out not only an area primarily about poverty alleviation but also primarily about their living conditions as an objective for their targeted poverty alleviation work to improve the villagers' sense of well-being.

Through interviews, it is found that all the poor households have received the financial aid from the School of Traditional Chinese Medicine of Jinan University, which reflects that the poor households have implemented the certification science and implemented the financial aid. At the same time, a large number of poor households have received the financial aid and benefited a large number of people. It shows that the School of Traditional Chinese Medicine of Jinan University has made proper use of the financial aid and science.

\section{Conflicts of Interest}

The authors declare no conflicts of interest regarding the publication of this paper. 


\section{References}

China Poverty Alleviation and Development Yearbook Editorial Committee (2015). China Poverty Alleviation and Development Yearbook. Jiangxi: Jiangxi University of Finance and Economics.

Zhou, Y. Y. (2019). Research on the Theory and Practice of the Communist Party of China in Poverty Alleviation in the New Era. Beijing: China Financial and Economic Publishing House.

Bi, J. Y. (2016). Research on the Poverty Measurement and Influencing Factors of Chinese Farmers. Hunan: Hunan Normal University.

Huang, Z. C. (2019). Research on China's Rural Household Poverty and Its Influencing Factors from the Perspective of Targeted Poverty Alleviation. Beijing: Chinese Academy of Agricultural Sciences. 